\title{
Quick assessment with controlled attenuation parameter for hepatic steatosis in children based on MRI-PDFF as the gold standard
}

Jaeseung Shin ${ }^{1}$, Myung-Joon Kim ${ }^{1,2}$, Hyun Joo Shin ${ }^{1,2}$, Haesung Yoon ${ }^{1,2}$, Seung Kim²,3, Hong Koh ${ }^{2,3+}$ and Mi-Jung Lee $\mathrm{L}^{1,2^{*}+}$ (iD

\begin{abstract}
Background: Controlled attenuation parameter (CAP) is a recently introduced, non-invasive and quantitative method to evaluate hepatic steatosis demonstrated in adults, but limited in obesity and not well evaluated in children. The aim of this study was to investigate the diagnostic performance for assessing hepatic steatosis grades using CAP in children based on MR proton density fat fraction (PDFF).

Methods: Children evaluated for non-alcoholic fatty liver disease (NAFLD) who were assessed for PDFF and CAP were enrolled retrospectively. Hepatic steatosis grades 0-3 were classified according to PDFF using cutoff values of 6, 17.5, and 23.3\%. Subgroup analyses were performed in non-obese and obese groups using the 95th percentile body mass index (BMI) as a cutoff and BMI30 group when BMI $>30 \mathrm{~kg} / \mathrm{m}^{2}$. Pearson's correlations between variables were also analyzed.

Results: In a total of 86 children, there were 53 in the obese group including 17 of the BMI30 group. CAP demonstrated $98.7 \%$ sensitivity and $80 \%$ specificity for diagnosing grades $1-3$ vs. grade 0 using a cutoff value of $241 \mathrm{~dB} / \mathrm{m}$ (area under the curve $=0.941, p<0.001$ ). The diagnostic performance for higher steatosis grades was suboptimal. CAP correlated with abdominal wall thickness in both obese $(r=0.549, p=0.001)$ and non-obese $(r=0.386, p=0.004)$ groups and did not correlate with PDFF in BMI30 group.
\end{abstract}

Conclusion: In children with NAFLD, CAP showed excellent diagnostic performance for differentiating presence and absence of hepatic steatosis using a cutoff value of $241 \mathrm{~dB} / \mathrm{m}$. However, CAP was limited in evaluating grades of steatosis, especially in children with $\mathrm{BMl}>30 \mathrm{~kg} / \mathrm{m}^{2}$.

Keywords: Fatty liver, Non-alcoholic fatty liver disease, Children, Controlled attenuation parameter, Proton density fat fraction

\section{Background}

Non-alcoholic fatty liver disease (NAFLD) is the most prevalent liver disease in children [1]. It has a large spectrum of presentation, can progress, and is associated with dyslipidemia, diabetes, and cardiovascular disease

\footnotetext{
*Correspondence: mjl1213@yuhs.ac

${ }^{\dagger}$ Hong Koh and Mi-Jung Lee contributed equally to this work.

'Department of Radiology and Research Institute of Radiological Science,

Severance Children's Hospital, Yonsei University College of Medicine,

50-1Yonsei-ro, Seodaemun-gu, Seoul 03722, South Korea

${ }^{2}$ Severance Pediatric Liver Disease Research Group, Severance Children's

Hospital, Yonsei University College of Medicine, Seoul, South Korea

Full list of author information is available at the end of the article
}

[2]. The prevalence of NAFLD was reported by race and ethnicity among a pediatric population as: Asian: $10.2 \%$, Black: 1.5\%, Hispanic: $11.8 \%$, and White: $8.6 \%$ [1]. With worldwide increasing trends of obesity and consequently NAFLD in children and adolescents, including South Korea as the prevalence of obesity increased from $6.8 \%$ in 1998 to $10.0 \%$ in 2013 [3, 4], there is increased risk of liver, cardiovascular and metabolic diseases throughout the lifespan. Although liver biopsy is the clinical standard for diagnosis, it is an invasive procedure with sampling errors and questionable inter- and intra-observer reliability [5]. Therefore, liver biopsy may not be ideal

(c) The Author(s). 2019 Open Access This article is distributed under the terms of the Creative Commons Attribution 4.0 International License (http://creativecommons.org/licenses/by/4.0/), which permits unrestricted use, distribution, and reproduction in any medium, provided you give appropriate credit to the original author(s) and the source, provide a link to the Creative Commons license, and indicate if changes were made. The Creative Commons Public Domain Dedication waiver (http://creativecommons.org/publicdomain/zero/1.0/) applies to the data made available in this article, unless otherwise stated. 
for all patients suspected of having NAFLD and for longitudinal follow-up, especially in children.

Non-invasive liver imaging techniques for hepatic steatosis have been emerging as a substitute for liver biopsy. MRI-estimated liver proton density fat fraction (PDFF) has shown a good correlation with histologic steatosis grade and the potential of clinical utility for the evaluation of NAFLD in both adults and children [6, 7]. Moreover, it not only has a high precision and reproducibility, but also greater reliability than histologic grading [8]. In a multicenter study for children with NAFLD, PDFF has shown high diagnostic accuracy to classify and predict histological steatosis grade, as well as to monitor changes in steatosis [9]. However, widespread use of PDFF might be limited in pediatric clinics due to high cost with need for expertise and longer examination time.

Transient elastography (TE) is an ultrasound-based technology used to estimate quantitative liver elasticity and is commonly used in clinical practice [10]. Controlled attenuation parameter (CAP), a novel technique to estimate hepatic steatosis using ultrasound attenuation based on the TE, shows correlation with histologic grades in adults [11-13]. Previous studies in pediatric liver disease have also shown encouraging outcomes for assessing steatosis using CAP [14]. CAP has advantages over MRI in terms of cost, accessibility, and quick assessment. However, the lack of optimal cutoff values for hepatic steatosis and technical limitation in obese patients [15], which is a risk factor for NAFLD [16], still remain in pediatric patients.

Therefore, in the present study, we aimed to evaluate the diagnostic performance of CAP for assessing hepatic steatosis in children based on PDFF with subgroup analyses based on body mass index (BMI).

\section{Methods}

\section{Patients}

This retrospective study was approved by the Institutional Review Board of our hospital. The acquisition of informed consent was waived. Pediatric patients aged 18 years or younger who underwent both abdominal MRI including PDFF and TE with CAP as a routine clinical practice for the evaluation of NAFLD in our hospital were included in this study. We included only the examinations within one month interval from January 2015 to December 2016. We excluded patients who had clinical or laboratory evidence of a liver diagnosis other than NAFLD (e.g., glycogen storage disease, drug, or virus) or alcohol consumption. We also reviewed laboratory results including aspartate aminotransferase (AST) and alanine aminotransferase (ALT) levels. Patients were divided into non-obese and obese groups based on BMI using the age and sex dependent 95th percentile as the cutoff [17]. We also classified patients with a BMI greater than $30 \mathrm{~kg} / \mathrm{m}^{2}$ among the obese group as a separate BMI30 group for additional analysis.

\section{Liver MRI including PDFF}

All MR scans were performed with patients lying supine in a 3-T scanner (Discovery MR750, GE Healthcare, Waukesha, WI, USA) with a 32-channel body coil without sedation. MR acquisition included single shot fast spin echo (SSFSE) T2-weighted axial and coronal images and iterative decomposition of water and fat with echo asymmetry and least-squares estimation quantification (IDEAL-IQ) axial images of the liver. SSFSE was used to identify anatomical locations and lesions in the liver as well as to measure abdominal wall thickness (AWT), which was defined as the thinnest skin-to-liver capsule distance of the abdominal wall surrounding the liver on an axial image at the main portal vein level. The IDEAL-IQ sequence is a three-dimensional volumetric imaging sequence for creating water, fat, in-phase, out-of-phase, R2* $(1 / \mathrm{T} 2 *)$, and fat fraction (water-triglyceride fat separation) maps of the liver from a single breath hold acquisition. The parameters of IDEAL-IQ were as follows: repetition time, $5.8 \mathrm{msec}$; field of view, $35-42 \mathrm{~cm}$; bandwidth, $125 \mathrm{kHz}$; flip angle, $3^{\circ}$; section thickness, $8 \mathrm{~mm}$; and a single three-dimensional image with 25 to 30 sections.

PDFF measurements in IDEAL-IQ were performed by placing regions of interest (ROIs) with the maximal area in the right hemiliver in three contiguous images. The ROIs were oval or circular in shape and excluded the liver boundary, fissures, gall bladder fossa, artifacts, and large blood vessels. Finally, the average value of the three measurements was used as the representative value. $\mathrm{Pa}$ tients' steatosis grades were grouped according to the established PDFF cutoff values for diagnosing histological steatosis grades 1 (S1), 2 (S2), and 3 (S3), and the PDFF cutoff values used were $6 \%$ for S1, $17.5 \%$ for S2, and $23.3 \%$ for $\mathrm{S} 3[9,18]$.

\section{TE for CAP}

CAP measurements were performed using Fibroscan (Echosens, France) by experienced technicians. TE was performed on the right lobe of the liver through the intercostal space with the participant lying supine with the right arm in maximal abduction. All participants underwent $\mathrm{TE}$ using an $\mathrm{M}$ or $\mathrm{XL}$ probe according to body size. The $M$ probe was used for patients with a thoracic perimeter more than $75 \mathrm{~cm}$, and the XL probe was used when the distance from the skin to the liver capsule was estimated over $25 \mathrm{~mm}$. CAP measured ultrasonic attenuation at $3.5 \mathrm{MHz}$ in the $\mathrm{M}$ probe and 2.5 $\mathrm{MHz}$ in the $\mathrm{XL}$ probe using signals that were acquired from TE. The median value of 10 valid measurements 
for a given participant was selected as the representative CAP value.

\section{Statistical analyses}

Statistical analyses were performed using the SPSS software package (IBM SPSS Statistics version 21; IBM Corp., Armonk, NY, USA) and MedCalc software package (version 18.2.1; MedCalc Software, Ostend, Belgium). Pearson's correlation coefficient (r) was calculated to evaluate the correlations between variables. To determine statistically significant differences in continuous variables between the non-obese and obese BMI groups, we used the one-way analysis of covariance with sex and age as covariates. For the comparison of PDFF and CAP in the BMI30 group, Mann Whitney test was used. According to steatosis groups based on PDFF, between-group differences were assessed by means of the Kruskal-Wallis test. Bonferroni's correction was applied to the post hoc analysis of the between-group comparison. Differences in categorical variables were evaluated using the chi-square test or Fisher's exact test as appropriate. Correlation coefficients between groups were compared with Fisher's r-to-z transformation. Receiver-operating curve (ROC) analysis was used to evaluate the diagnostic performance of CAP for each steatosis grade. The optimal cutoff values were selected to maximize the Youden index. A $p$-value $<0.05$ was considered statistically significant.

\section{Results}

\section{Patient characteristics}

Table 1 shows the characteristics and laboratory results of all study patients and each subgroup. A total of 86 patients (M: $\mathrm{F}=62: 24)$ with a mean age of $13.1 \pm 2.7$ years (range, 7-18 years) were included in this study. The time interval between MRI and TE was 0-19 days with the mean of $2.4 \pm 5.0$ days. Among the included patients, 33 were classified in the non-obese group, and the remaining 53 patients belonged to the obese group. Seventeen patients also met the criteria for inclusion in the BMI30 group.

There was no significant difference in age or gender between the non-obese and obese groups; however, AWT was greater in the obese group compared to the non-obese group $(2.8 \pm 0.6 \mathrm{~cm}$ vs. $2.1 \pm 0.5 \mathrm{~cm}, p<$ $0.001)$. The mean AST $(70.9 \pm 53.2 \mathrm{IU} / \mathrm{L}$ vs. $46.2 \pm 39.8$ $\mathrm{IU} / \mathrm{L}, p=0.025)$ and ALT $(119.0 \pm 90.7 \mathrm{IU} / \mathrm{L}$ vs. $71.2 \pm$ $66.9 \mathrm{IU} / \mathrm{L}, p=0.011)$ values were significantly higher in the obese group compared to the non-obese group. The logarithmic transformed AST $(1.77 \pm 0.28$ vs. $1.61 \pm 0.32$, $p=0.015)$ and ALT $(2.00 \pm 0.29$ vs. $1.72 \pm 0.47, p=0.004)$ values were also significantly different between the two groups. The other laboratory results were not significantly different between the two groups (Table 1).

There was a positive correlation between AWT and BMI $(\mathrm{r}=0.807 ; 95 \%$ confidence interval [CI]: 0.718, 0.870). For the CAP assessment of TE, M and XL probes

Table 1 Patient characteristics including comparison between patients with a non-obese body mass index (BMI) (non-obese group) and a BMl greater than the 95th percentile (obese group)

\begin{tabular}{|c|c|c|c|c|}
\hline & \multirow{2}{*}{$\begin{array}{l}\text { All patients } \\
(n=86)\end{array}$} & \multicolumn{3}{|l|}{ Group comparison } \\
\hline & & Non-obese group $(n=33)$ & Obese group $(n=53)$ & $p$-value \\
\hline Age (y) & $13.1 \pm 2.7$ & $12.4 \pm 2.4$ & $13.5 \pm 2.8$ & 0.067 \\
\hline Female $(n, \%)$ & $24(31.3)$ & $12(36.4)$ & $12(22.6)$ & $0.168^{*}$ \\
\hline $\mathrm{BMI}\left(\mathrm{kg} / \mathrm{m}^{2}\right)$ & $26.3 \pm 4.9$ & $21.6 \pm 2.6$ & $29.2 \pm 3.5$ & $<0.001$ \\
\hline $\mathrm{AWT}(\mathrm{cm})$ & $2.5 \pm 0.7$ & $2.1 \pm 0.5$ & $2.8 \pm 0.6$ & $<0.001$ \\
\hline AST (U/L) & $61.4 \pm 49.7$ & $46.2 \pm 39.8$ & $70.9 \pm 53.2$ & $0.015^{\dagger}$ \\
\hline $\mathrm{ALT}(\mathrm{U} / \mathrm{L})$ & $100.7 \pm 85.2$ & $71.2 \pm 66.9$ & $119.0 \pm 90.7$ & $0.004^{+}$ \\
\hline Total bilirubin (mg/dL) & $0.6 \pm 0.3$ & $0.5 \pm 0.2$ & $0.6 \pm 0.3$ & 0.861 \\
\hline Albumin (g/dL) & $4.6 \pm 0.3$ & $4.6 \pm 0.3$ & $4.6 \pm 0.2$ & 0.702 \\
\hline ALP (IU/L) & $206.5 \pm 100.5$ & $222.6 \pm 99.0$ & $196.5 \pm 101.0$ & 0.728 \\
\hline Cholesterol (mg/dL) & $190.7 \pm 35.9$ & $185.8 \pm 38.0$ & $193.8 \pm 34.5$ & 0.229 \\
\hline $\mathrm{TG}(\mathrm{mg} / \mathrm{dL})$ & $159.5 \pm 90.4$ & $151.0 \pm 86.0$ & $163.3 \pm 93.2$ & $0.888^{\dagger}$ \\
\hline $\mathrm{HDL}(\mathrm{mg} / \mathrm{dL})$ & $44.3 \pm 10.0$ & $45.8 \pm 12.2$ & $43.5 \pm 8.7$ & 0.501 \\
\hline $\mathrm{LDL}(\mathrm{mg} / \mathrm{dL})$ & $117.1 \pm 34.4$ & $113.9 \pm 38.8$ & $118.6 \pm 32.3$ & 0.356 \\
\hline PDFF (\%) & $22.6 \pm 12.8$ & $20.2 \pm 14.5$ & $24.1 \pm 11.6$ & 0.139 \\
\hline $\mathrm{CAP}(\mathrm{dB} / \mathrm{m})$ & $310.5 \pm 46.5$ & $293.6 \pm 51.5$ & $321.1 \pm 40.2$ & 0.053 \\
\hline
\end{tabular}

* Chi-square test was performed to compare the two groups

${ }^{\dagger}$ Logarithmic transformation before group comparison was performed in order to satisfy normality assumption. All the $p$-values of boldface are less than 0.05 Notes: AWT abdominal wall thickness, AST aspartate aminotransferase, $A L T$ alanine aminotransferase, $A L P$ alkaline phosphatase, $T G$ triglycerides, $H D L$ high-density lipoprotein, $L D L$ low-density lipoprotein, PDFF proton density fat fraction, CAP controlled attenuation parameter 
were used for eighty-two and four patients, respectively. The four patients used XL probe were all in the BMI30 group. Patient characteristics according to steatosis group based on PDFF are summarized in Table 2.

\section{Diagnostic performance of CAP}

Both PDFF and CAP values were measured in all patients. The PDFF values ranged from $2.6-48.0 \%$ with a mean of $22.6 \pm 12.8 \%$. The CAP values ranged from 157 to $400 \mathrm{~dB} / \mathrm{m}$ with a mean of $310.5 \pm 46.5 \mathrm{~dB} / \mathrm{m}$. According to PDFF, patients were divided into four steatosis groups, S0 (PDFF $<6 \%, n=10$ ), S1 (PDFF $6-17.4 \%, n=$ 25), S2 (PDFF $17.5-23.2 \%, n=14$ ), and S3 (PDFF $\geq 23.3 \%, n=37$ ). The CAP values in each steatosis group are shown in Fig. 1. The mean and median CAP values were $228.4 \pm 45.9 \mathrm{~dB} / \mathrm{m}$ and $222.5 \mathrm{~dB} / \mathrm{m}$ in $\mathrm{S} 0,309.0 \pm$ $38.9 \mathrm{~dB} / \mathrm{m}$ and $308 \mathrm{~dB} / \mathrm{m}$ in $\mathrm{S} 1,313.2 \pm 33.1 \mathrm{~dB} / \mathrm{m}$ and $301 \mathrm{~dB} / \mathrm{m}$ in $\mathrm{S} 2$, and $332.7 \pm 28.3 \mathrm{~dB} / \mathrm{m}$ and $329 \mathrm{~dB} / \mathrm{m}$ in S3, respectively. The mean CAP value of S0 showed a statistically significant difference from the other groups $(p<0.001)$, but there were no significant differences among S1, S2, and S3.

In ROC analysis, a CAP value of $241 \mathrm{~dB} / \mathrm{m}$ represented an optimal cutoff value for diagnosis of S1-S3 vs. S0, with a sensitivity of $98.7 \%$ (95\% CI: $92.9,100.0)$, a specificity of $80.0 \%$ (95\% CI: 44.4, 97.5), and area under the curve (AUC) of 0.941 (95\% CI: 0.868, 0.980) (Table 3, Fig. 1). Positive predictive value (PPV) and negative predictive value (NPV) for the presence of steatosis on a CAP value of $241 \mathrm{~dB} / \mathrm{m}$ was 96.2 and $87.5 \%$, respectively. A CAP value of $213 \mathrm{~dB} / \mathrm{m}$ showed $100 \%$ sensitivity $(95 \%$ CI: $95.3,100.0)$ and $40 \%$ specificity (95\% CI: 12.2, 73.8), whereas a CAP value of $311 \mathrm{~dB} / \mathrm{m}$ showed $57.9 \%$ sensitivity (95\% CI: $46.0,69.1)$ and $100 \%$ specificity (95\% CI: $69.2,100.0)$ to diagnose the presence of steatosis. The optimal CAP cutoff values of $299 \mathrm{~dB} / \mathrm{m}$ and $303 \mathrm{~dB} / \mathrm{m}$ were obtained to predict S2-S3 vs. S0-S1 (sensitivity $80.4 \%$ with $95 \%$ CI of $66.9-90.2$, specificity $51.4 \%$ with 95\% CI of 34.0-68.6, PPV 70.0\%, NPV 65.4\%, AUC 0.734 with $95 \% \mathrm{CI}$ of $0.627-0.823$ ) and S3 vs. S0-S2 (sensitivity $81.1 \%$ with $95 \%$ CI of $64.8-92.0$, specificity $57.1 \%$ with $95 \%$ CI of $42.2-71.2$, PPV $57.7 \%$, NPV $79.4 \%$, AUC 0.752 with $95 \%$ CI of $0.647-0.839$ ), respectively. The AUC was higher for the diagnosis of $\mathrm{S} 1-\mathrm{S} 3$ vs. S0 compared with that of S2-S3 vs. S0-S1 ( $p=$ $0.011)$ and that of S3 vs. S0-S2 $(p=0.015)$. However, it was not different for the diagnosis of $\mathrm{S} 2-\mathrm{S} 3$ vs. $\mathrm{S} 0-\mathrm{S} 1$ and that of S3 or not $(p>0.999)$.

\section{Relationships in different body habitus groups}

PDFF was positively correlated with CAP in all patients $(\mathrm{r}=0.486 ; 95 \%$ CI: 0.306, 0.633; $p<0.001$ ) (Table 4). According to subgroup analysis, the correlation coefficient between PDFF and CAP was 0.585 (95\% CI: 0.302, $0.773)$ in the non-obese group $(n=33, p<0.001)$ and 0.354 (95\% CI: $0.093,0.570)$ in the obese group $(n=53$,

Table 2 Patient characteristics according to steatosis grades based on MR proton density fat fraction

\begin{tabular}{|c|c|c|c|c|c|}
\hline & \multicolumn{5}{|l|}{ Steatosis grades } \\
\hline & SO $(n=10)$ & $\mathrm{S} 1(n=25)$ & $\mathrm{S} 2(n=14)$ & S3 $(n=37)$ & $p$-value \\
\hline Age $(y)$ & $13(9-17)$ & $14(7-18)$ & $13(10-18)$ & $12(9-18)$ & 0.209 \\
\hline Female $(n, \%)$ & $5(50.0)$ & $8(32.0)$ & $5(35.7)$ & $6(16.2)$ & $0.134^{\dagger}$ \\
\hline $\mathrm{BMI}\left(\mathrm{kg} / \mathrm{m}^{2}\right)$ & $20.6(14.7-25.9)$ & $26.3(18.0-38.5)$ & $26.5(19.2-30.9)$ & $28.3(19.3-40.6)$ & 0.002 \\
\hline $\mathrm{AWT}(\mathrm{cm})$ & $1.7(1-2.9)$ & $2.7(1.3-4.3)$ & $2.5(1.8-3.2)$ & $2.8(1.8-4.7)$ & 0.003 \\
\hline AST (U/L) & $21.5(17-26)$ & $52(12-241)$ & $36(17-197)$ & $63(25-179)$ & $<0.001$ \\
\hline ALT $(U / L)$ & $15(8-28)$ & $95(8-430)$ & $61(22-234)$ & $96(23-346)$ & $<0.001$ \\
\hline Total bilirubin (mg/dL) & $0.6(0.3-0.8)$ & $0.6(0.3-1.2)$ & $0.5(0.3-1.6)$ & $0.5(0.3-0.9)$ & 0.089 \\
\hline Albumin (g/dL) & $4.4(4.2-5.1)$ & $4.6(3.7-5.2)$ & $4.5(4.0-4.9)$ & $4.6(4.3-5.1)$ & 0.249 \\
\hline ALP (IU/L) & $217(69-325)$ & $152(38-405)$ & $201(59-308)$ & $242(65-466)$ & 0.032 \\
\hline Cholesterol (mg/dL) & $161.5(127-231)$ & $184(144-306)$ & $205(151-222)$ & $191(125-276)$ & 0.044 \\
\hline $\mathrm{TG}(\mathrm{mg} / \mathrm{dL})$ & $91(44-419)$ & $117(58-240)$ & $144.5(55-322)$ & $158(54-487)$ & 0.045 \\
\hline $\mathrm{HDL}(\mathrm{mg} / \mathrm{dL})$ & $50.5(26-66)$ & $39(26-70)$ & $44(28-50)$ & $47(30-65)$ & 0.133 \\
\hline $\mathrm{LDL}(\mathrm{mg} / \mathrm{dL})$ & $79.1(60.2-106.8)$ & 117.6 (71.2-235.8) & $128(90.8-183)$ & $107.8(66.6-205)$ & 0.010 \\
\hline PDFF (\%) & $3.5(2.6-5.2)$ & $13.9(6.8-17)$ & $19.5(17.8-23.1)$ & 33.7 (24-48) & $<0.001$ \\
\hline $\mathrm{CAP}(\mathrm{dB} / \mathrm{m})$ & $222.5(157-311)$ & $308(216-400)$ & $301(271-384)$ & $329(272-399)$ & $<0.001$ \\
\hline
\end{tabular}

The values are median (range) or number (percentage)

*Non-parametric method, Kruskal-Wallis test, was performed to compare groups, unless otherwise indicated

${ }^{\dagger}$ Chi-square test was performed to compare groups. All the $p$-values of boldface are less than 0.05

Notes: AWT abdominal wall thickness, AST aspartate aminotransferase, ALT alanine aminotransferase, ALP alkaline phosphatase, TG triglycerides, HDL high-density lipoprotein, $L D L$ low-density lipoprotein, PDFF proton density fat fraction, CAP controlled attenuation parameter 


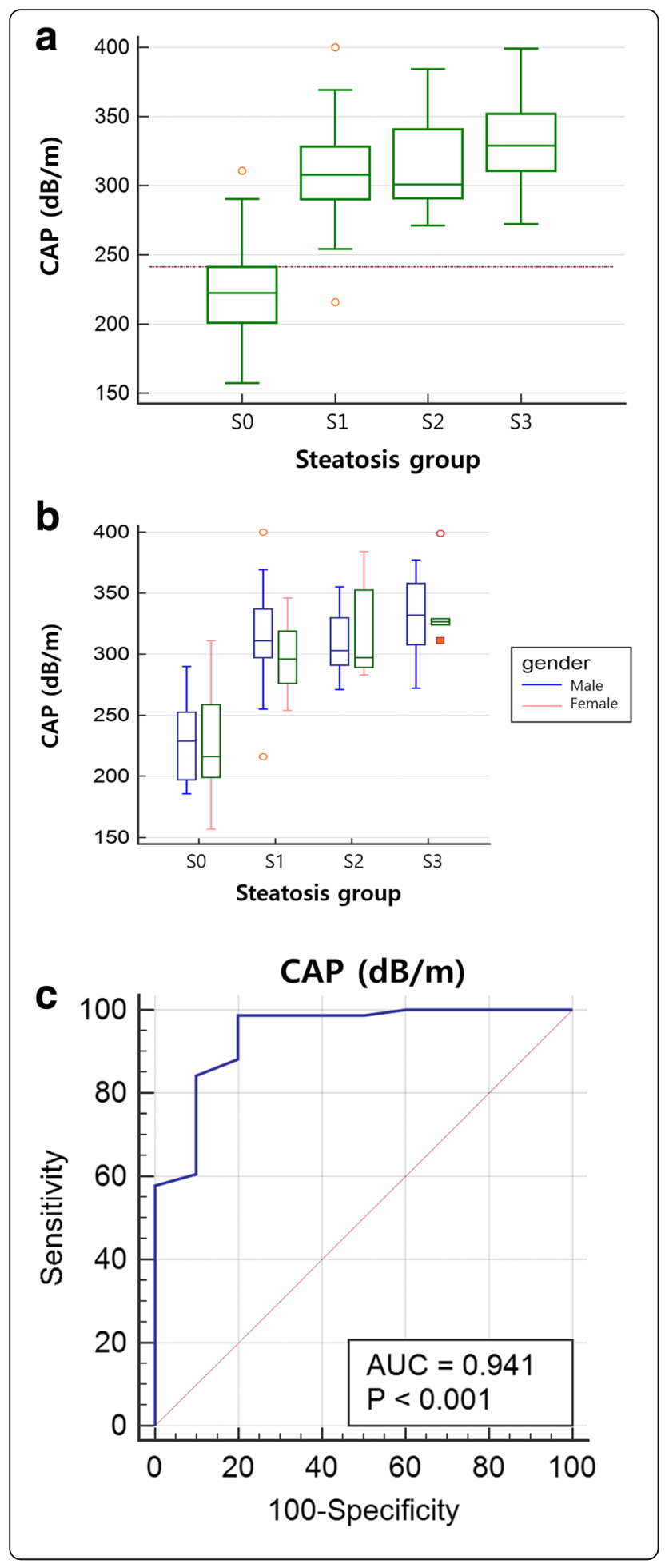

Fig. 1 Comparison of steatosis groups using controlled attenuation parameter (CAP) value. (A and B) CAP values in each steatosis group based on MR proton density fat fraction (PDFF) of whole group (a) and divided by gender (b) are demonstrated in a box plot. Hepatic steatosis grades 0-3 (SO-S3) were classified using the PDFF cutoff values of $6,17.5$, and $23.3 \%$. The mean and median CAP values were 228.4 and $222.5 \mathrm{~dB} / \mathrm{m}$ in S0, 309 and $308 \mathrm{~dB} / \mathrm{m}$ in S1, 313.2 and 301 $\mathrm{dB} / \mathrm{m}$ in S2, and 332.7 and $329 \mathrm{~dB} / \mathrm{m}$ in S3, respectively. The dash line means the cutoff value of $241 \mathrm{~dB} / \mathrm{m}$ to differentiate S0 vs. S1-S3. (c) On receiver operating characteristic curve analysis, the optimal cutoff value for diagnosis of S1-S3 vs. S0 was $241 \mathrm{~dB} / \mathrm{m}$ with $98.7 \%$ sensitivity (95\% confidence interval [CI], 92.9-100.0), 80.0\% specificity (95\% Cl, 44.4-97.5), and 0.941 of area under the curve (95\% $\mathrm{Cl}, 0.868-0.980)$

$p=0.009)$, the difference of which was not statistically significant $(\mathrm{z}=1.30, p=0.097)$ (Fig. 2).

With respect to AWT, male $(2.61 \pm 0.63 \mathrm{~cm})$ had significantly higher AWT than female did $(2.39 \pm 0.69 ; p=$ 0.045). PDFF was not correlated with AWT (Table 4). However, CAP was positively correlated with AWT $(\mathrm{r}=$ 0.517; 95\% CI: 0.343, 0.657; $p<0.001$ ). In subgroup analysis, only CAP was positively correlated with AWT in both the non-obese group $(\mathrm{r}=0.549 ; 95 \% \mathrm{CI}$ : 0.253 , $0.751 ; p=0.001)$ and obese group $(\mathrm{r}=0.386 ; 95 \% \mathrm{CI}$ : $0.129,0.594 ; p=0.004)$. AWT was not correlated with PDFF in either the non-obese or obese group.

In the BMI30 group, CAP values were obtained using $\mathrm{M}$ probe in 13 patients and XL probe in four patients. The median values of the PDFF and CAP in BMI30 group patients were 19 and $20 \%$ in PDFF, and $326 \mathrm{~dB} / \mathrm{m}$ and $370 \mathrm{~dB} / \mathrm{m}$ in CAP, obtained with $\mathrm{M}$ and XL probes, respectively. PDFF was not correlated with CAP $(\mathrm{r}=$ 0.212 ; $95 \%$ CI: $-0.300,0.629 ; p=0.413)$. AWT was not correlated with PDFF $(\mathrm{r}=-0.338$; 95\% CI: $-0.704,0.170$; $p=0.185)$ and CAP ( $\mathrm{r}=0.221 ; 95 \%$ CI: $-0.291,0.634 ; p=$ $0.394)$.

\section{Discussion}

NAFLD is becoming increasingly recognized as an important health problem for pediatric patients [19]. Because there is no established effective therapy, early risk stratification for disease progression is considered an important component of patient management [20]. In this retrospective study, we compared values for hepatic steatosis in pediatric NAFLD cases obtained noninvasively using PDFF and CAP techniques. Based on ROC analysis for diagnosing hepatic steatosis grades using established PDFF cutoff values, we suggest a CAP cutoff value of $241 \mathrm{~dB} / \mathrm{m}$ for the presence of steatosis. However, CAP cutoff values for steatosis grade 2 or higher were not reliable. Although there were moderate correlations between PDFF and CAP values in all patients $(r=0.486)$, there was no correlation between PDFF and CAP in the BMI30 group. CAP values were positively correlated 
Table 3 Diagnostic performance of CAP for hepatic steatosis grades (S0-S3)

\begin{tabular}{lllllll}
\hline & Cutoff $(\mathrm{dB} / \mathrm{m})$ & Sensitivity $(\%, 95 \% \mathrm{Cl})$ & Specificity $(\%, 95 \% \mathrm{Cl})$ & PPV (\%) & NPV (\%) & AUC (95\% Cl) \\
\hline S0 vs. S1-S3 ( $\geq 6 \%)$ & 241 & $98.7(92.9-100.0)$ & $80.0(44.4-97.5)$ & 96.2 & 87.5 & $0.941(0.868-0.980)$ \\
S0-S1 vs. S2-S3 ( $\geq 17.5 \%)$ & 299 & $80.4(66.9-90.2)$ & $51.4(34.0-68.6)$ & 70.0 & 65.4 & $0.734(0.627-0.823)$ \\
S0-S2 vs. S3 ( $\geq 23.3 \%)$ & 303 & $81.1(64.8-92.0)$ & $57.1(42.2-71.2)$ & 57.7 & 79.4 & $0.752(0.647-0.839)$ \\
\hline
\end{tabular}

Notes: CAP, controlled attenuation parameter; $\mathrm{Cl}$, confidence interval; PPV, positive predictive value; NPV, negative predictive value; AUC, area under the curve

with AWT. Therefore, CAP can be a good screening tool to diagnose the presence of steatosis in children, but is probably limited during disease follow up or in children with high BMI, though longitudinal data are lacking.

MRI-based hepatic fat quantification is useful in pediatric patients not only for diagnosis and grading [9], but also for treatment monitoring [21]. PDFF exhibits an excellent correlation with hepatic steatosis, especially the macrovesicular form, which is common in both adult and pediatric NAFLD [22, 23]. PDFF also quantifies steatosis of the whole liver, whereas liver biopsy only evaluates a small portion of the liver. However, liver MRI including PDFF in young children may require sedation with additional examination time and cost. Therefore, more convenient and cheaper diagnostic tests are required for screening and disease monitoring in patients with NAFLD, especially in children.

$\mathrm{TE}$ is widely used to evaluate liver elasticity and has been validated in large cohort studies for diagnosing and staging liver fibrosis [24]. CAP calculates the attenuation of ultrasonic signals acquired by $\mathrm{TE}$, postulating that ultrasound propagation is affected by fat tissues on the path. CAP has been shown to have an excellent correlation with actual liver fat percentage in non-to-mildly obese patients with NAFLD [25] and can distinguish the absence or presence of steatosis in adult chronic liver disease [26, 27]. However, only one study with children has demonstrated the ability of CAP to detect steatosis, although differentiation among histopathologic grade of steatosis was not successful with small number of patients and fair overlap [14]. In that study, the suggested cutoff value of CAP for predicting steatosis was $225 \mathrm{~dB} /$ $m$ with $87 \%$ sensitivity, $83 \%$ specificity, and an AUC of
0.93 , which is comparable to the cutoff of $241 \mathrm{~dB} / \mathrm{m}$ derived from our ROC analysis. In another study assessing CAP compared with ultrasound grading and the other imperfect gold standard in children, a cutoff point of $249 \mathrm{~dB} / \mathrm{m}$ for predicting steatosis was identified with a sensitivity of $72 \%$ and a specificity of $98-100 \%$ [28], which is also comparable with our result.

In a prospective adult cohort study with PDFF as the gold standard [5], the cut off values for PDFF $\geq 5 \%$ and $\geq 10 \%$ were $288 \mathrm{~dB} / \mathrm{m}$ (AUC $0.80,95 \% \mathrm{CI}$ $0.70-0.90$ ) and $304 \mathrm{~dB} / \mathrm{m}$ (AUC 0.87 , 95\% CI 0.80 0.94), respectively. In this study, the authors have identified that demographical characteristics, such as high BMI and high prevalence of type 2 diabetes, may affect the accurate assessment of CAP. The portion examined with the XL probe, which is reported to show higher value of CAP than using $M$ probe [29], is also different with our study. A recent individual patient meta-analysis of CAP for assessing hepatic steatosis with various etiologies has shown that CAP values were influenced by several covariates, including BMI and the presence of NAFLD or non-alcoholic steatohepatitis (NASH), and suggested cutoffs of $248 \mathrm{~dB} / \mathrm{m}$ for grade $1,268 \mathrm{~dB} / \mathrm{m}$ for grade 2 , and $280 \mathrm{~dB} / \mathrm{m}$ for grade 3 steatosis [13]. However, in another study from 2016, evaluating both PDFF and CAP in adult NAFLD [12], the cutoff values for hepatic steatosis grades 1,2 , and 3 were 5.2, 11.3, and $17.1 \%$ for PDFF and $236 \mathrm{~dB} / \mathrm{m}, 270 \mathrm{~dB} / \mathrm{m}$, and $302 \mathrm{~dB} / \mathrm{m}$ for CAP, respectively. The cutoff values for CAP and PDFF were both different in our study. Moreover, discrimination among steatosis grades 1, 2, and 3 with CAP was suboptimal in the present study.

Table 4 Correlation values for hepatic steatosis in all patients, the non-obese group, obese group, and BMI30 (BMI > $\left.30 \mathrm{~kg} / \mathrm{m}^{2}\right)$ group

\begin{tabular}{|c|c|c|c|c|c|c|c|c|c|}
\hline & & \multicolumn{2}{|l|}{$\begin{array}{l}\text { All patients } \\
(n=86)\end{array}$} & \multicolumn{2}{|c|}{$\begin{array}{l}\text { Non-obese group } \\
(n=33)\end{array}$} & \multicolumn{2}{|l|}{$\begin{array}{l}\text { Obese group } \\
(n=53)\end{array}$} & \multicolumn{2}{|l|}{$\begin{array}{l}\text { BMI30 group } \\
(n=17)\end{array}$} \\
\hline & & $r(95 \% \mathrm{Cl})$ & $\overline{p \text {-value }}$ & $r(95 \% \mathrm{Cl})$ & $\overline{p \text {-value }}$ & $r(95 \% \mathrm{Cl})$ & $\overline{p \text {-value }}$ & $r(95 \% \mathrm{Cl})$ & $p$-value \\
\hline \multirow[t]{2}{*}{ PDFF } & CAP & $\begin{array}{l}0.486 \\
(0.306-0.633)\end{array}$ & $<0.001$ & $\begin{array}{l}0.585 \\
(0.302-0.773)\end{array}$ & $<0.001$ & $\begin{array}{l}0.354 \\
(0.093-0.570)\end{array}$ & 0.009 & $\begin{array}{l}0.212 \\
(-0.300-0.629)\end{array}$ & 0.413 \\
\hline & AWT & $\begin{array}{l}0.179 \\
(-0.003-0.377)\end{array}$ & 0.099 & $\begin{array}{l}0.318 \\
(-0.028-0.596)\end{array}$ & 0.071 & $\begin{array}{l}-0.023 \\
(-0.300-0.249)\end{array}$ & 0.925 & $\begin{array}{l}-0.338 \\
(-0.704-0.170)\end{array}$ & 0.185 \\
\hline CAP & AWT & $\begin{array}{l}0.517 \\
(0.343-0.657)\end{array}$ & $<0.001$ & $\begin{array}{l}0.549 \\
(0.253-0.751)\end{array}$ & 0.001 & $\begin{array}{l}0.386 \\
(0.129-0.594)\end{array}$ & 0.004 & $\begin{array}{l}0.221 \\
(-0.291-0.634)\end{array}$ & 0.394 \\
\hline
\end{tabular}

Notes: $\mathrm{Cl}$ confidence interval, PDFF proton density fat fraction, CAP controlled attenuation parameter, AWT abdominal wall thickness. All the $p$-values of boldface are less than 0.05 


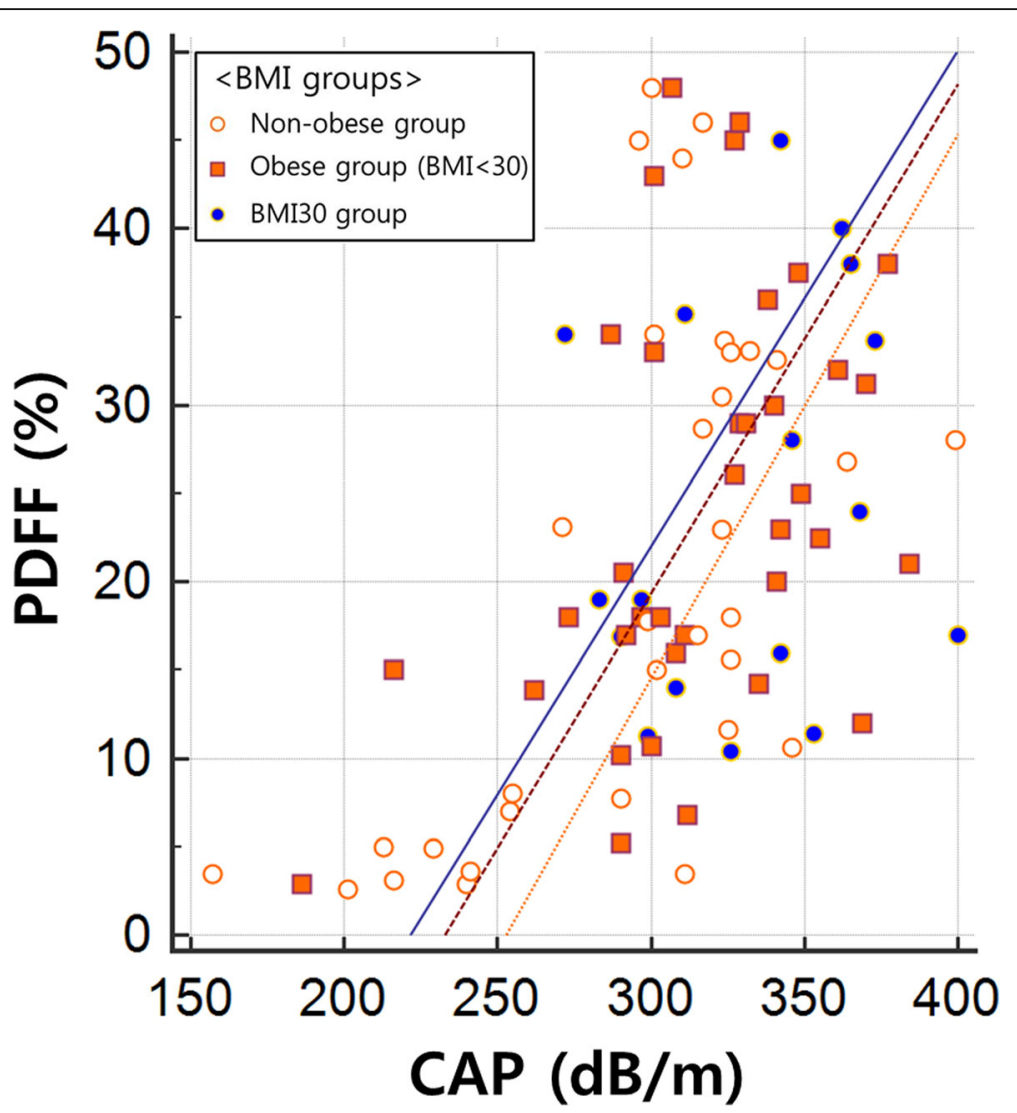

Fig. 2 A scatter plot of hepatic steatosis between PDFF and CAP. CAP values were positively correlated with PDFF in all patients ( $r=0.486 ; 95 \%$ confidence interval $[\mathrm{Cl}]$ : 0.306, 0.633; $p<0.001)$. In subgroups according to body mass index (BMI), the r was $0.585(95 \% \mathrm{Cl}: 0.302,0.773 ; p<0.001)$ in the non-obese group (BMI<95th percentile) and $0.354(95 \% \mathrm{Cl}: 0.093,0.570 ; p=0.009)$ in the obese group (BMI $\geq 95$ th percentile). However, PDFF and CAP values were not correlated in the BMI30 $\left(\mathrm{BMI}>30 \mathrm{~kg} / \mathrm{m}^{2}\right)$ group

One possible explanation for the discrepancy in cutoff values is that the histopathologic nature of pediatric NAFLD is different from that of adult disease. NAFLD patterns are characterized by a zone 1 distribution of steatosis, inflammation, and fibrosis in young children in contrast to the most intense change around the central vein (predominantly in zones 2 and 3) in adults [30]. This different pathologic distribution might affect the result of CAP on the basis of ultrasound technology. Other possible reasons could be the higher BMI and higher AST/ALT of patients in the present study, which could affect CAP results, as demonstrated in a study in adults [13]. Indeed, CAP values positively correlated with AWT $(\mathrm{r}=0.517, p<0.001)$, while PDFF did not. It could be from the difference of measurement way as PDFF measures a proportion of fat molecules and CAP measures physical properties of the liver. Whereas PDFF only evaluate liver parenchyma to separate fat and water signal, ultrasound signal on TE and CAP has no choice but to pass through the subcutaneous fat layer between TE probe and liver parenchyma. It is possible that the subcutaneous fat layer might affect the CAP measurement increasing ultrasound attenuation, especially in high BMI patients with increased AWT. A recent systematic review evaluated the factors affecting liver stiffness measurements using TE [31] and waist circumference was included as an affecting factor which is considered to be the same context as the CAP and BMI of this study. In addition, gender was included as covariate since different adipose distribution by gender might affect the result of CAP. In the present study, males had significantly higher AWT than females did, contrary to the previous study showing markedly higher subcutaneous thickness in females [32, 33]. Significantly higher rate of obesity and metabolic syndrome in Korean boys than in girls $[3,4]$ and small number of female patients $(n=24)$ in this study might affect the discrepancy. Additional studies with histopathologic correlations and analysis by gender will be needed to validate the effects of pathologic differences and AWT on CAP.

There are intrinsic limitations of both TE and MRI for the evaluation of NAFLD. Neither imaging modality can reliably discriminate NASH from simple steatosis [34]. A wide range of optimal cutoffs for the diagnosis of NASH 
has been reported and likely depends on the prevalence of advanced fibrosis in the study population [34]. In addition, current imaging methods cannot detect the lobular arrangement of steatosis, which is useful to distinguish the pediatric pattern of NAFLD [35].

This study also has several limitations. First, this was a retrospective study that included patients suspected with NAFLD who were referred by a pediatrician; thus, our results may have been affected by selection bias. Second, due to the lack of liver histopathologic data, we were unable to directly correlate and compare MRI and TE values with histologic grades of hepatic steatosis. Although PDFF based on MR imaging has demonstrated good correlation with histological steatosis grade, there were considerable overlap in PDFF results among steatosis grades [6,7]. Therefore, histologic evaluation is still needed to determine the effects of simple steatosis and steatohepatitis on CAP values. Third, the number of patients, especially low proportion of the S0 group $(n=$ 10), might be small to determine the optimal cutoff point, resulting in uncertainty of estimated cutoff value. However, in the retrospective study only including clinically suspected NAFLD patients, this is a reasonable result because there is no need to perform PDFF and CAP, without suspicion of NAFLD in pediatric patients. Moreover, the number of female patients is not enough for additional analysis by gender. Fourth, because there were no agreed criteria for severely obese patients in pediatric field, a BMI30 cutoff was applied. Nevertheless, the proportion of the BMI30 group was still low, so a further study to focus on severely obese patients is required.

\section{Conclusions}

CAP can differentiate between the presence and absence of hepatic steatosis using a cutoff value of $241 \mathrm{~dB} / \mathrm{m}$ with a sensitivity of $98.7 \%$ and a specificity of $80.0 \%$ in pediatric patients with NAFLD. However, CAP was not reliable in evaluating higher grade steatosis. Moreover, caution should be exercised in interpreting CAP data in obese children, especially in children with a BMI greater than $30 \mathrm{~kg} / \mathrm{m}^{2}$, from the effect of increased AWT.

\footnotetext{
Abbreviations

ALT: Alanine aminotransferase; AST: Aspartate aminotransferase; AUC: Area under the curve; AWT: Abdominal wall thickness; BMI: Body mass index; CAP: Controlled attenuation parameter; IDEAL-IQ: Iterative decomposition of water and fat with echo asymmetry and least-squares estimation quantification; NAFLD: Non-alcoholic fatty liver disease; NASH: Non-alcoholic steatohepatitis; PDFF: Proton density fat fraction; ROC: Receiver-operating curve; ROI: Region of interest; SSFSE: Single shot fast spin echo; TE: Transient elastography
}

\section{Acknowledgements}

Not applicable.

Funding

Not applicable.

\section{Availability of data and materials}

The datasets used and/or analyzed during the current study are available from the corresponding author on reasonable request.

\section{Authors' contributions}

JS collected and analyzed the data and was a major contributor in writing the manuscript. MK analyzed the data and corrected the manuscript. HJS and $\mathrm{HY}$ collected the data and performed statistical analysis. SK reviewed and edited the manuscript. HK analyzed and interpreted the data and wrote the manuscript. $\mathrm{ML}$ analyzed and interpreted the data and was a major contributor in writing the manuscript. All authors read and approved the final manuscript.

\section{Ethics approval and consent to participate}

This retrospective study was approved by the Institutional Review Board of Severance Hospital (reference number of 1-2016-0060). The acquisition of informed consent was waived.

\section{Consent for publication}

Not applicable.

\section{Competing interests}

The authors declare that they have no competing interests.

\section{Publisher's Note}

Springer Nature remains neutral with regard to jurisdictional claims in published maps and institutional affiliations.

\section{Author details}

${ }^{1}$ Department of Radiology and Research Institute of Radiological Science, Severance Children's Hospital, Yonsei University College of Medicine, 50-1Yonsei-ro, Seodaemun-gu, Seoul 03722, South Korea. ${ }^{2}$ Severance Pediatric Liver Disease Research Group, Severance Children's Hospital, Yonsei University College of Medicine, Seoul, South Korea. ${ }^{3}$ Department of Pediatrics, Severance Children's Hospital, Yonsei University College of Medicine, Seoul, South Korea.

Received: 31 October 2018 Accepted: 3 April 2019

Published online: 15 April 2019

\section{References}

1. Schwimmer JB, Deutsch R, Kahen T, Lavine JE, Stanley C, Behling C. Prevalence of fatty liver in children and adolescents. Pediatrics. 2006;118(4): 1388-93.

2. Schwimmer JB. Clinical advances in pediatric nonalcoholic fatty liver disease. Hepatology. 2016;63(5):1718-25.

3. Ha KH, Kim DJ. Epidemiology of childhood obesity in Korea. Endocrinol Metab. 2016;31(4):510-8

4. Kang Y, Park S, Kim S, Koh H. Estimated prevalence of adolescents with nonalcoholic fatty liver disease in Korea. J Korean Med Sci. 2018;33(14).

5. Caussy $C$, Alquiraish MH, Nguyen $P$, Hernandez C, Cepin S, Fortney LE, Ajmera V, Bettencourt R, Collier S, Hooker J, et al. Optimal threshold of controlled attenuation parameter with MRI-PDFF as the gold standard for the detection of hepatic steatosis. Hepatology. 2018;67(4):1348-59.

6. Permutt Z, Le TA, Peterson MR, Seki E, Brenner DA, Sirlin C, Loomba R. Correlation between liver histology and novel magnetic resonance imaging in adult patients with non-alcoholic fatty liver disease - MRI accurately quantifies hepatic steatosis in NAFLD. Aliment Pharmacol Ther. 2012;36(1): 22-9.

7. Schwimmer JB, Middleton MS, Behling C, Newton KP, Awai HI, Paiz MN, Lam J, Hooker JC, Hamilton G, Fontanesi J, et al. Magnetic resonance imaging and liver histology as biomarkers of hepatic steatosis in children with nonalcoholic fatty liver disease. Hepatology. 2015;61(6):1887-95.

8. Dulai PS, Sirlin CB, Loomba R. MRI and MRE for non-invasive quantitative assessment of hepatic steatosis and fibrosis in NAFLD and NASH: clinical trials to clinical practice. J Hepatol. 2016;65(5):1006-16.

9. Middleton MS, Van Natta ML, Heba ER, Alazraki A, Trout AT, Masand P, Brunt EM, Kleiner DE, Doo E, Tonascia J, et al. Diagnostic accuracy of magnetic resonance imaging hepatic proton density fat fraction in pediatric nonalcoholic fatty liver disease. Hepatology. 2018;67(3):858-72. 
10. Barr RG, Ferraioli G, Palmeri ML, Goodman ZD, Garcia-Tsao G, Rubin J, Garra B, Myers RP, Wilson SR, Rubens D, et al. Elastography assessment of liver fibrosis: Society of Radiologists in ultrasound consensus conference statement. Radiology. 2015;276(3):845-61.

11. Sasso M, Beaugrand M, de Ledinghen V, Douvin C, Marcellin P, Poupon R, Sandrin L, Miette V. Controlled attenuation parameter (CAP): a novel VCTE guided ultrasonic attenuation measurement for the evaluation of hepatic steatosis: preliminary study and validation in a cohort of patients with chronic liver disease from various causes. Ultrasound Med Biol. 2010;36(11): $1825-35$.

12. Imajo K, Kessoku T, Honda Y, Tomeno W, Ogawa Y, Mawatari H, Fujita K, Yoneda M, Taguri M, Hyogo $\mathrm{H}$, et al. Magnetic resonance imaging more accurately classifies steatosis and fibrosis in patients with nonalcoholic fatty liver disease than transient Elastography. Gastroenterology. 2016;150(3):62637 e627.

13. Karlas T, Petroff D, Sasso M, Fan JG, Mi YQ, de Ledinghen V, Kumar M, Lupsor-Platon M, Han KH, Cardoso AC, et al. Individual patient data metaanalysis of controlled attenuation parameter (CAP) technology for assessing steatosis. J Hepatol. 2017:66(5):1022-30.

14. Desai NK, Harney S, Raza R, Al-lbraheemi A, Shillingford N, Mitchell PD, Jonas MM. Comparison of controlled attenuation parameter and liver biopsy to assess hepatic steatosis in pediatric patients. J Pediatr. 2016;173: 160-164.e161.

15. Foucher J, Castera L, Bernard PH, Adhoute X, Laharie D, Bertet J, Couzigou $P$, de Ledinghen $V$. Prevalence and factors associated with failure of liver stiffness measurement using FibroScan in a prospective study of 2114 examinations. Eur J Gastroenterol Hepatol. 2006;18(4):411-2.

16. Bedogni G, Miglioli L, Masutti F, Tiribelli C, Marchesini G, Bellentani S. Prevalence of and risk factors for nonalcoholic fatty liver disease: the Dionysos nutrition and liver study. Hepatology. 2005;42(1):44-52.

17. Moon JS, Lee SY, Nam CM, Choi JM, Choe BK, Seo JW, Oh KW, Jang MJ, Hwang SS, Yoo MH, et al. 2007 Korean National Growth Charts: review of developmental process and an outlook. Korean J Pediatr. 2008;51(1):1-25.

18. Shin HJ, Kim HG, Kim MJ, Koh H, Kim HY, Roh YH, Lee MJ. Normal range of hepatic fat fraction on dual- and triple-echo fat quantification MR in children. PLoS One. 2015;10(2):e0117480.

19. Kohli R, Sunduram S, Mouzaki M, Ali S, Sathya P, Abrams S, Xanthakos SA, Vos M, Schwimmer JB. Pediatric nonalcoholic fatty liver disease: a report from the expert committee on nonalcoholic fatty liver disease (ECON). J Pediatr. 2016;172:9-13.

20. Chalasani N, Younossi Z, Lavine JE, Diehl AM, Brunt EM, Cusi K, Charlton M, Sanyal AJ. The diagnosis and management of non-alcoholic fatty liver disease: practice guideline by the American Association for the Study of Liver Diseases, American College of Gastroenterology, and the American Gastroenterological Association. Hepatology. 2012;55(6):2005-23.

21. Koh H, Kim S, Kim MJ, Kim HG, Shin HJ, Lee MJ. Hepatic fat quantification magnetic resonance for monitoring treatment response in pediatric nonalcoholic steatohepatitis. World J Gastroenterol. 2015;21(33):9741-8.

22. Fishbein M, Castro F, Cheruku S, Jain S, Webb B, Gleason T, Stevens WR. Hepatic MRI for fat quantitation: its relationship to fat morphology, diagnosis, and ultrasound. J Clin Gastroenterol. 2005;39(7):619-25.

23. Pacifico L, Martino MD, Catalano C, Panebianco V, Bezzi M, Anania C, Chiesa C. T1-weighted dual-echo MRI for fat quantification in pediatric nonalcoholic fatty liver disease. World J Gastroenterol. 2011;17(25):3012-9.

24. Wong WW, Vergniol J, Wong GL, Foucher J, Chan HL, Le Bail B, Choi PC, Kowo M, Chan AW, Merrouche W, et al. Diagnosis of fibrosis and cirrhosis using liver stiffness measurement in nonalcoholic fatty liver disease. Hepatology. 2010;51(2):454-62.

25. Fujimori N, Tanaka N, Shibata S, Sano K, Yamazaki T, Sekiguchi T, Kitabatake $\mathrm{H}$, Ichikawa Y, Kimura T, Komatsu M, et al. Controlled attenuation parameter is correlated with actual hepatic fat content in patients with non-alcoholic fatty liver disease with none-to-mild obesity and liver fibrosis. Hepatol Res. 2016.

26. Sasso M, Miette V, Sandrin L, Beaugrand M. The controlled attenuation parameter (CAP): a novel tool for the non-invasive evaluation of steatosis using Fibroscan. Clin Res Hepatol Gastroenterol. 2012;36(1):13-20.

27. Chon YE, Jung KS, Kim SU, Park JY, Park YN, Kim do Y, Ahn SH, Chon CY, Lee HW, Park Y, et al. Controlled attenuation parameter (CAP) for detection of hepatic steatosis in patients with chronic liver diseases: a prospective study of a native Korean population. Liver international : official journal of the International Association for the Study of the Liver. 2014;34(1):102-9.
28. Ferraioli G, Calcaterra V, Lissandrin R, Guazzotti M, Maiocchi L, Tinelli C, De Silvestri A, Regalbuto C, Pelizzo G, Larizza D, et al. Noninvasive assessment of liver steatosis in children: the clinical value of controlled attenuation parameter. BMC Gastroenterol. 2017;17(1):61.

29. Chan WK, Nik Mustapha NR, Wong GL, Wong WW, Mahadeva S. Controlled attenuation parameter using the FibroScan(R) XL probe for quantification of hepatic steatosis for non-alcoholic fatty liver disease in an Asian population. United European Gastroenterol J. 2017;5(1):76-85.

30. Kleiner DE, Makhlouf HR. Histology of nonalcoholic fatty liver disease and nonalcoholic steatohepatitis in adults and children. Clinics in liver disease. 2016;20(2):293-312.

31. Bazerbachi F, Haffar S, Wang Z, Cabezas J, Arias-Loste MT, Crespo J, Darwish-Murad S, Ikram MA, Olynyk JK, Gan E, et al. Range of Normal liver stiffness and factors associated with increased stiffness measurements in apparently healthy individuals. Clinical gastroenterology and hepatology : the official clinical practice. journal of the American Gastroenterological Association. 2019;17(1):54-64.e51.

32. Ayonrinde OT, Olynyk JK, Beilin LJ, Mori TA, Pennell CE, de Klerk N, Oddy WH, Shipman P, Adams LA. Gender-specific differences in adipose distribution and adipocytokines influence adolescent nonalcoholic fatty liver disease. Hepatology. 2011;53(3):800-9.

33. Ayonrinde OT, Olynyk JK, Marsh JA, Beilin L, Mori TA, Oddy WH, Adams LA. Childhood adiposity trajectories and risk of nonalcoholic fatty liver disease in adolescents. J Gastroenterol Hepatol. 2015;30(1):163-71.

34. Ajmera V, Loomba R. Can Elastography differentiate isolated fatty liver from nonalcoholic steatohepatitis? Semin Liver Dis. 2018;38(1):14-20.

35. Cassidy FH, Yokoo T, Aganovic L, Hanna RF, Bydder M, Middleton MS, Hamilton G, Chavez AD, Schwimmer JB, Sirlin CB. Fatty liver disease: MR imaging techniques for the detection and quantification of liver steatosis. Radiographics : a review publication of the Radiological Society of North America, Inc. 2009;29(1):231-60.

\section{Ready to submit your research? Choose BMC and benefit from:}

- fast, convenient online submission

- thorough peer review by experienced researchers in your field

- rapid publication on acceptance

- support for research data, including large and complex data types

- gold Open Access which fosters wider collaboration and increased citations

- maximum visibility for your research: over $100 \mathrm{M}$ website views per year

At BMC, research is always in progress.

Learn more biomedcentral.com/submissions 